\title{
Modulation of Hippocampal Acetylcholine Release and Spontaneous Alternation Scores by Intrahippocampal Glucose Injections
}

\author{
Michael E. Ragozzino, Shanthi N. Pal, Katharine Unick, Mark R. Stefani, and Paul E. Gold \\ Department of Psychology, Gilmer Hall, University of Virginia, Charlottesville, Virginia 22903
}

Recent evidence indicates that systemic glucose treatment enhances memory while producing a corresponding increase in hippocampal acetylcholine (ACh) output. The present experiments examined whether unilateral intrahippocampal infusions of glucose would enhance spontaneous alternation performance and whether there would be a corresponding increase in ACh output in the ipsilateral and contralateral hippocampus. Extracellular ACh was assessed in samples collected at $12 \mathrm{~min}$ intervals using in vivo microdialysis with HPLC with electrochemical detection. Twelve minutes after a unilateral infusion of artificial cerebrospinal fluid (CSF) or glucose $(6.6 \mathrm{~mm})$, rats were tested in a cross maze for spontaneous alternation behavior with concurrent microdialysis collection. In two experiments, glucose infusions significantly increased alternation scores (67.5 and 59\%) compared with CSF controls (42.4 and 39.5\%, respectively). In both experiments, behavioral testing resulted in increased ACh output in the hippocampus. Glucose adminis- tration at the time of alternation tests enhanced ACh output beyond that of behavioral testing alone both ipsilateral $(+93.8 \%)$ and contralateral $(+85 \%)$ to the infusion site, as compared with ACh output $(+36.1 \%$ and $+55.5 \%)$ of CSF controls. Glucose infusions did not affect hippocampal ACh output in rats kept in a holding chamber. These results suggest that glucose may enhance alternation scores by modulating $\mathrm{ACh}$ release. The findings also indicate that unilateral glucose infusions increase hippocampal ACh output both ipsilateral and contralateral to the site of injection. Furthermore, glucose increased ACh output only during maze testing, suggesting that specific behavioral demands, perhaps requiring activation of cholinergic neurons, determine the efficacy of glucose in modulating ACh release.

Key words: glucose; memory; learning; hippocampus; acetylcholine; microdialysis
Systemic administration of glucose enhances memory on a wide range of tests in humans and rodents (Gold, 1986; Messier and White, 1987; Hall et al., 1989; Manning et al., 1990, 1993; Packard and White, 1990). Such findings suggest that glucose may directly modulate brain systems critical for mnemonic functioning. In support of this view, glucose injections into the lateral ventricles or into specific brain areas, i.e., the medial septum and amygdala, modulate memory (Lee et al., 1988; Ragozzino et al., 1992; Ragozzino and Gold, 1994a).

Thus, although glucose can act directly on the brain to enhance cognitive functions, the neural mechanisms underlying glucose enhancement of memory remain unclear. Circulating glucose readily crosses from blood to brain through a facilitated transport mechanism to serve as the major energy source for the CNS (Gibbs et al., 1942; Pardridge, 1983). In addition to its critical metabolic functions, glucose also serves as a substrate for the synthesis of certain neurotransmitters. One possibility is that glucose acts on specific neurotransmitter systems to facilitate memory. To unravel what neurotransmitter systems glucose may modulate to augment memory, several experiments have examined the effects of glucose administered in combination with

Received June 2, 1997; revised Nov. 21, 1997; accepted Dec. 1, 1997.

This research was supported by grants from the National Institute of Neurological Disorders and Stroke (NS32914) and the National Institute of Aging (AG07648).

Correspondence should be addressed to Dr. Paul E. Gold, Department of Psychology, University of Virginia, Charlottsville, VA 22903.

Dr. Ragozzino's and Dr. Unick's present address: Department of Psychology, University of Utah, Salt Lake City, UT 84112.

Copyright (C) 1998 Society for Neuroscience $0270-6474 / 98 / 181595-07 \$ 05.00 / 0$ other pharmacological treatments on memory and other behavioral and neural measures. One set of results indicates that glucose may facilitate the actions of cholinergic neurons. Specifically, systemic administration of glucose attenuates memory impairments, paradoxical sleep deficits, and hyperactivity induced by muscarinic cholinergic antagonists (Stone et al., 1987, 1988a, 1991, 1995).

Recent findings support the view that circulating glucose can modulate central ACh release. For example, glucose injections at doses that facilitate memory reverse the effects of morphineinduced decreases in hippocampal ACh output (Ragozzino et al., 1994b; Ragozzino and Gold, 1995a). Conversely, glucose potentiates an enhancement in hippocampal ACh output produced by scopolamine, a muscarinic cholinergic antagonist (Durkin et al., 1992).

Recent evidence demonstrates that systemic glucose injections concomitantly potentiate an increase in hippocampal ACh release and enhance spontaneous alternation scores (Ragozzino et al., 1996). These results suggest that glucose may act directly in the hippocampal formation to augment $\mathrm{ACh}$ release and enhance memory. The first experiment determined whether glucose can act directly in the hippocampal formation to modulate $\mathrm{ACh}$ release by measuring the effects of unilateral glucose infusions on hippocampal ACh output during spontaneous alternation testing and while rats remain in a holding chamber. Because there is a paucity of neurochemical results indicating how neurotransmitter release in one hippocampal hemisphere influences neurotransmitter release in the other hemisphere, the second experiment determined whether modulation of hippocampal ACh release in 
one hemisphere would affect ACh release in the contralateral hemisphere. This experiment tested whether unilateral hippocampal infusions of glucose would alter ACh output in the contralateral hemisphere during behavioral testing and during resting conditions.

\section{MATERIALS AND METHODS}

Subjects. Male Sprague Dawley rats (Charles River Breeding Laboratories, Wilmington, MA) weighing $300-350 \mathrm{gm}$ at the time of surgery served as subjects. Rats were housed individually with food and water available ad libitum. A $12 \mathrm{hr}$ light/dark cycle (lights on at 7 A.M.) was maintained.

Surgery. Twenty minutes before they were anesthetized with sodium pentobarbital $(50 \mathrm{mg} / \mathrm{kg}$, i.p.), rats received atropine sulfate $(0.2 \mathrm{ml}$ of a $540 \mathrm{mg} / \mathrm{ml}$ solution, i.p.). After they were anesthetized, each rat was placed in a stereotaxic frame with the nose bar set at $5.0 \mathrm{~mm}$ above the interaural line according to the atlas of Pellegrino et al. (1979). In the first experiment, a plastic guide cannula (CMA/12 type; Carnegie Medicin, Stockholm) was lowered into the hippocampal formation at the stereotaxic coordinates $3.8 \mathrm{~mm}$ caudal to bregma, $5.0 \mathrm{~mm}$ lateral to the midline, and $3.8 \mathrm{~mm}$ ventral from dura. In the second experiment, the procedure and stereotaxic coordinates were the same except that guide cannulae were bilaterally implanted. Five jeweler's screws were placed in the skull surrounding the cannula(e) and cemented in place with dental acrylic (Plastics One, Roanoke, VA).

Microdialysis procedure. The microdialysis procedure was similar to that described previously (Ragozzino et al., 1996). Beginning $2 \mathrm{~d}$ after surgery, rats were handled each day for $\sim 5 \mathrm{~min}$. At least 1 week after surgery, rats were randomly assigned to either a spontaneous alternation or a "resting" condition. All rats were tested during their light phase (8 A.M.-4 P.M.). A $3 \mathrm{~mm}$ dialysis probe (CMA/12; Carnegie Medicin) was inserted through the guide cannula. The dialysis probe was perfused continuously at a rate of $2.1 \mathrm{ml} / \mathrm{min}$ with artificial cerebrospinal fluid $\left(128 \mathrm{~mm} \mathrm{NaCl} / 2.5 \mathrm{~mm} \mathrm{KCl} / 1.3 \mathrm{mM} \mathrm{CaCl}_{2} / 2.1 \mathrm{~mm}\right.$ $\mathrm{MgCl}_{2} / 21 \mathrm{~mm} \quad \mathrm{NaH}_{2} \mathrm{PO}_{4} / 1.3 \mathrm{~mm} \mathrm{Na}_{2} \mathrm{HPO}_{4} / 3.3 \mathrm{~mm}$ glucose and brought to $\mathrm{pH} 7.0$ by $\mathrm{NaOH}$ ) that contained the acetylcholinesterase inhibitor neostigmine $(1 \mu \mathrm{M})$.

Spontaneous alternation condition. The spontaneous alternation condition was identical for both experiments unless noted otherwise. Rats were first placed in a black plexiglas chamber $(23 \times 30 \times 30 \mathrm{~cm})$, and microdialysis was then started. Perfusate collected for the first 45-60 min was not analyzed, to allow equilibration between the brain tissue and perfusion solution before sampling. Subsequently, samples were collected at $12 \mathrm{~min}$ intervals. Samples, assayed for ACh content, that were collected during a period of $1 \mathrm{~h}$ (five total) served as baseline rates for ACh output. At the beginning of the second hour, rats were randomly assigned to either the artificial CSF (aCSF) or glucose $(6.6 \mathrm{~mm})$ group. The number of rats in each group was six. For the glucose group, aCSF with glucose at $6.6 \mathrm{~mm}$ was perfused for a total of $24 \mathrm{~min}$ (two samples). In the aCSF group, the perfusion solution (standard aCSF) remained unchanged, i.e., it contained $3.3 \mathrm{~mm}$ glucose.

At the beginning of the second postinjection sample (12 min after injection), rats were removed from the holding chamber and placed in a four-arm cross maze. The maze $(85 \mathrm{~cm}$ height $)$ was constructed of wood painted gray and contained a central platform $(25 \mathrm{~cm}$ diameter $)$, from which radiated four symmetrical arms $(55 \mathrm{~cm}$ long $\times 10 \mathrm{~cm}$ wide), with $12 \mathrm{~cm}$ walls. The treatment-test interval was based on past behavioral experiments in which rats were tested $15 \mathrm{~min}$ after intracranial injections (Ragozzino and Gold, 1994a; Ragozzino et al., 1995b). After they were placed in the central platform, rats were allowed to traverse the maze freely for $12 \mathrm{~min}$. The number and sequence of entries were recorded; an alternation was defined as entry into four different arms on overlapping quintuple sets. Five consecutive arm choices within the total set of arm choices made up a quintuple set. A quintuple set consisting of arm choices B,A,C,B,D was considered an alternation. A quintuple set consisting of arm choices B,A,D,B,A was not considered an alternation. Using this procedure, possible alternation sequences are equal to the number of arm entries minus four. The percent alternation score is equal to the ratio of (actual alternations/possible alternations) $\times 100$; chance performance on this task is $22 \%$. Only data from rats that made at least $10 \mathrm{arm}$ choices were included in the behavioral and biochemical analyses.

After behavioral testing, rats were returned to the holding chamber. Three additional microdialysis samples were collected. Thus, five base- line and five postinjection samples were collected for a total of 10 samples.

Resting condition. The habituation, baseline collection, and treatment groups $(n=6)$ were the same as in the spontaneous alternation condition. After baseline collection, microdialysis samples were collected for an additional $60 \mathrm{~min}$ (five samples) while the rat remained in the Plexiglas chamber.

Acetylcholine assay. Samples $(20 \mathrm{ml})$ were assayed for ACh using HPLC with electrochemical detection. ACh was separated from choline by a reverse-phase analytical column (Chromspher $5 \mathrm{C} 18,100 \times 3 \mathrm{~mm}$; Chrompack, Middleburg, The Netherlands). Subsequently, an enzymatic postcolumn reactor containing acetylcholinesterase (EC 3.1.1.7; Sigma VI-S, Sigma, St. Louis, MO) and choline oxidase (EC 1.1.3.17; Sigma) converted the ACh to choline and acetate and the choline to betaine. The final conversion to hydrogen peroxide was electrochemically detected by a platinum electrode held at a potential of $+525 \mathrm{mV}$. The mobile phase containing $0.2 \mathrm{~mm}$ dibasic potassium phosphate, $1.0 \mathrm{~mm}$ tetramethylammonium hydroxide, $0.3 \mathrm{~mm}$ EDTA, and $0.0005 \%$ Kathon CG was delivered at a rate $0.6 \mathrm{ml} / \mathrm{min}$ by a solvent delivery system (PM-80; Bioanalytical Systems, West Lafayette, IN). ACh and choline peaks were quantified by comparison to peak heights of ACh and choline standard solutions. The detection limit was $50 \mathrm{fmol}$, and the assay was completed within $7 \mathrm{~min}$.

Histology. After they were tested, rats received a lethal dose of sodium pentobarbital. A dialysis probe dipped in ink was then inserted through the hippocampal guide cannula. This procedure enhanced determination of the dialysis probe location. This was followed by an intracardial perfusion with $0.9 \%$ saline and a $10 \%$ formalin solution. Brains were removed and placed in a $30 \%$ sucrose/formalin solution. The brains were frozen and cut in coronal sections $(40 \mathrm{~mm})$ on a cryostat. The sections were mounted onto slides and dried. The sections were first analyzed unstained. Subsequently, the sections were stained with cresyl violet. After staining, the sections were examined again to determine whether any cellular damage had occurred during the implantation.

Statistical analyses. For analysis of the microdialysis data, the raw values were converted to percentages from the baseline output for each subject. The baseline output was calculated from the mean of the first five samples for each subject. Baseline ACh output did not vary significantly across groups in either Experiment 1 or $2\left(F_{(3,19)}=1.12\right.$ and $F_{(3,18)}=$ 1.09 , respectively; $p>0.3)$. Mean baseline ACh output was $3.0 \pm 0.2$ $\mathrm{pmol} / 20 \mu \mathrm{l}$ samples in Experiment 1 and $2.8 \pm 0.2 \mathrm{pmol} / 20 \mu \mathrm{l}$ samples in Experiment 2.

The percent values from the groups were analyzed by a two-way ANOVA with one-repeated measure. Simple main-effect tests were applied to compare groups at specific times, and Dunnett's test was applied for comparison to baseline levels.

Student $t$ tests were used to compare differences in the percent alternation scores and the number of arm entries.

\section{RESULTS}

\section{Experiment 1: Effects of unilateral glucose infusions on ipsilateral hippocampal ACh release and spontaneous alternation performance.}

\section{Spontaneous alternation condition}

The results describing ACh output during spontaneous alternation testing are shown in Figure 1. CSF controls exhibited an increase in hippocampal ACh output $(+36.1 \%)$ during spontaneous alternation testing. In CSF rats, ACh levels remained elevated above basal levels $12 \mathrm{~min}$ after testing but returned to basal levels by 24 min after behavioral testing. Intrahippocampal infusions of glucose $(6.6 \mathrm{~mm})$ potentiated the increase in hippocampal ACh output (+93.8\%) during behavioral testing. As shown in Figure 1, CSF controls exhibited a significant increase in hippocampal ACh release during spontaneous alternation performance compared with basal levels $(p<0.01)$. $\mathrm{ACh}$ output in CSF rats remained significantly enhanced $(+35.3 \%)$ for the sample after behavioral testing $(p<0.01)$ but was not significantly different from basal levels 24 min after behavioral testing $(p>0.05)$.

A unilateral perfusion of glucose $(6.6 \mathrm{~mm})$ during behavioral 


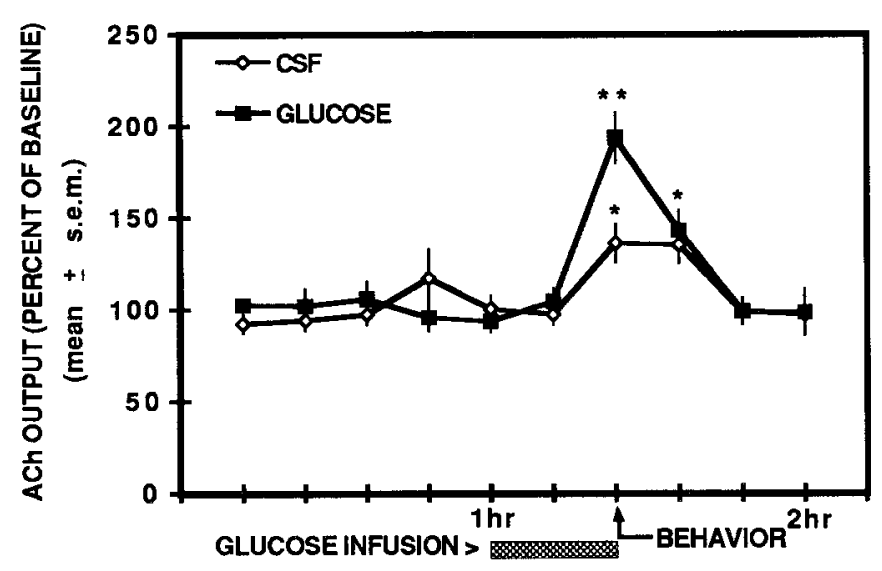

Figure 1. Effects of unilateral hippocampal infusions of glucose and artificial cerebrospinal fluid on ipsilateral hippocampal ACh output during the behavioral condition. ACh output was significantly enhanced during spontaneous alternation in CSF controls. Glucose infusions (6.6 $\mathrm{mM}$ ) significantly increased ACh output during testing compared with CSF controls. ACh output in the sample after testing remained significantly elevated in the CSF and glucose groups; however, there was no significant difference in ACh output between the groups. * $p<0.01$ versus baseline; ${ }^{*} p<0.01$ versus CSF.

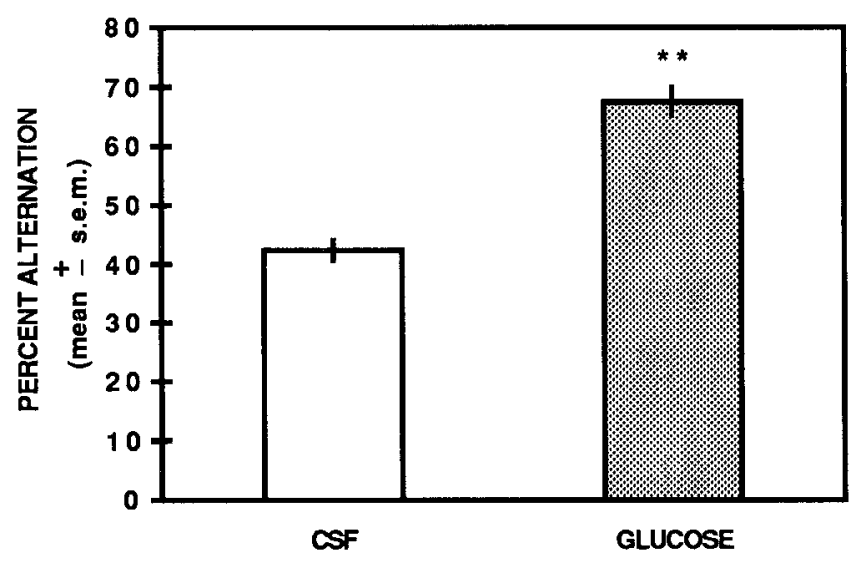

Figure 2. Unilateral hippocampal infusions of glucose enhance spontaneous alternation performance. Glucose $(6.6 \mathrm{~mm})$ significantly increased spontaneous alternation performance compared with that of CSF controls. ${ }^{* *} p<0.01$ versus CSF.

testing significantly potentiated ACh output compared with that of CSF controls $\left(F_{(1,10)}=11.06 ; p<0.01\right)$. In glucose-treated rats, $\mathrm{ACh}$ release remained significantly elevated above basal levels 12 min after behavioral testing $(p<0.01)$ but did not differ significantly from ACh release in CSF controls $\left(F_{(1,10)}=0.29\right.$; $p>0.05)$. Twenty-four minutes after spontaneous alternation testing, ACh levels of glucose-treated rats were not significantly different from those of basal levels $(p>0.05)$.

The spontaneous alternation scores are illustrated in Figure 2. Analysis of the percent alternation scores indicated a significant difference between CSF- and glucose-treated rats $\left[t_{(10)}=8.18\right.$; $p<0.01]$. CSF controls had a mean percent alternation score of $42.5 \pm 1.7$ SEM compared with a mean percent alternation score of $67.5 \pm 2.4$ in glucose-treated rats.

In contrast to the spontaneous alternation scores, analysis of the number of arm choices did not reveal a significant difference in the number of arm entries between the two groups $\left(t_{(10)}=1.20 ; p>0.05\right)$. The mean number of arms entered for

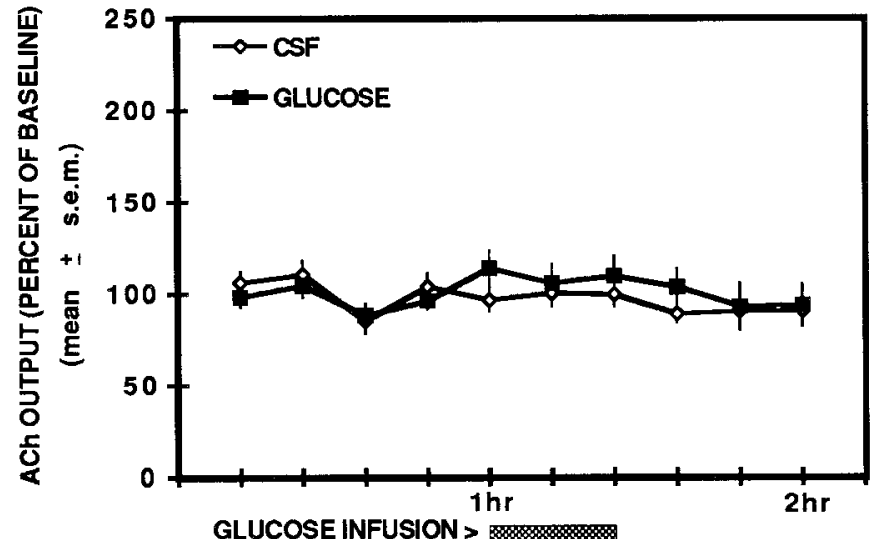

Figure 3. Effects of unilateral hippocampal injections of glucose and artificial cerebrospinal fluid on ipsilateral hippocampal ACh output in the resting condition. Injections of glucose $(6.6 \mathrm{~mm})$ or CSF did not alter hippocampal ACh output in the resting condition.

CSF controls was $21.2 \pm 1.4$, and for glucose-treated rats it was $25.3 \pm 3.2$.

\section{Resting condition}

ACh output in the two groups during the resting condition is shown in Figure 3. The findings indicate that neither glucose nor CSF treatment altered ipsilateral hippocampal ACh output during this condition. An ANOVA indicated that there were no significant differences between the groups $\left(F_{(1,9)}=1.65\right.$; $p>0.05)$, across time $\left(F_{(9,81)}=0.69 ; p>0.05\right)$, nor was there a significant interaction between treatment and time $\left(F_{(9,81)}=\right.$ $0.57 ; p>0.05)$.

\section{Experiment 2: The effects of unilateral glucose infusions on contralateral hippocampal ACh release and spontaneous alternation performance Spontaneous alternation condition}

The results of contralateral hippocampal ACh output during the behavioral testing condition are illustrated in Figure 4. Similar to the findings in Experiment 1, CSF controls showed an increase in contralateral hippocampal ACh output during spontaneous alternation testing, but ACh output returned to basal levels by $24 \mathrm{~min}$ after behavioral testing. A unilateral glucose infusion into the hippocampal formation potentiated the elevation in $\mathrm{ACh}$ release in the contralateral hippocampal formation. During behavioral testing, CSF controls exhibited a significant increase in hippocampal ACh release compared with basal levels $(p<0.01)$. ACh levels in CSF controls remained significantly enhanced 12 min after behavioral testing $(p<0.01)$ but were not significantly different from baseline levels 24 min after testing $(p>0.05)$.

Glucose treatment significantly potentiated contralateral hippocampal ACh output compared with that of CSF controls during spontaneous alternation testing $\left(F_{(1,10)}=5.47 ; p<0.05\right)$. In the sample immediately after testing, ACh output in glucosetreated rats was still significantly increased compared with basal levels $(p<0.01)$ but not significantly different compared with that of CSF controls $\left(F_{(1,10)}=4.26 ; p>0.05\right)$. Twenty-four minutes after testing, ACh output in glucose-treated rats was not significantly different from baseline levels $(p>0.05)$.

The results after spontaneous alternation testing are shown in Figure 5. As observed in Experiment 1, a unilateral glucose infusion into the hippocampal formation significantly enhanced 


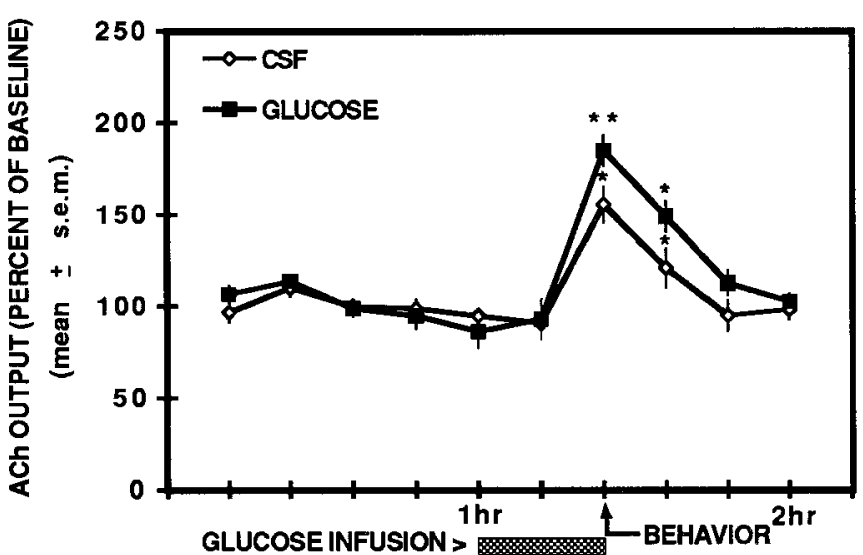

Figure 4. Effects of unilateral hippocampal infusions of glucose and artificial cerebrospinal fluid on contralateral hippocampal ACh output during the behavioral condition. ACh output was significantly enhanced during spontaneous alternation in CSF controls. Glucose infusions (6.6 $\mathrm{mM}$ ) significantly increased ACh output during testing compared with CSF controls. ACh output in the sample after testing remained significantly elevated in the CSF and glucose groups; however, there was no significant difference in ACh output between the groups. ${ }^{*} p<0.01$ versus baseline; ${ }^{*} p<0.05$ versus CSF.

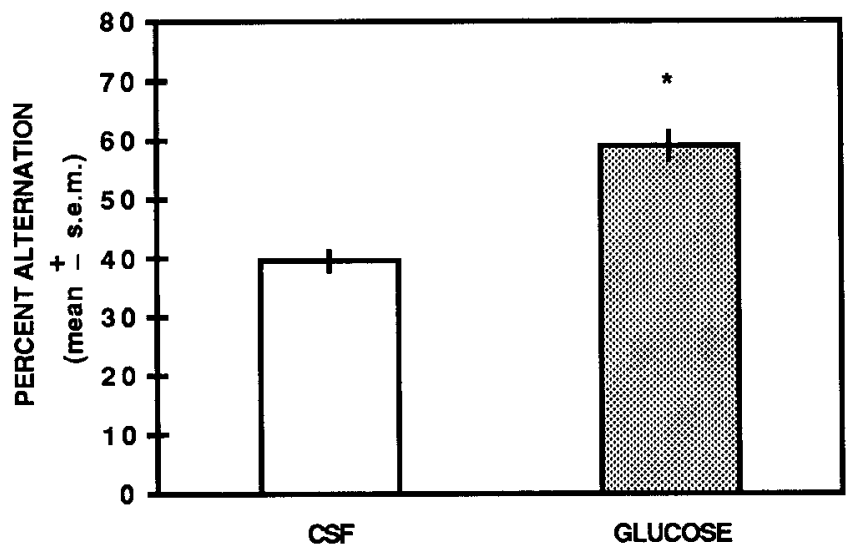

Figure 5. Unilateral hippocampal infusions of glucose enhance spontaneous alternation performance. Glucose $(6.6 \mathrm{~mm})$ significantly increased spontaneous alternation performance compared with that of CSF controls. ${ }^{*} p<0.05$ versus CSF.

spontaneous alternation performance compared with that of CSF controls $\left(t_{(10)}=2.46 ; p<0.05\right)$. In contrast, the number of arms entered was not significantly different between the groups $\left(t_{(10)}=1.42 ; p>0.05\right)$. The mean number of arms entered for CSF controls was $16.0 \pm 2.1$ and for glucosetreated rats was $21.7 \pm 3.4$.

\section{Resting condition}

The findings of the treatments in the resting condition are illustrated in Figure 6. Neither CSF nor glucose treatment modified contralateral hippocampal ACh output. An ANOVA indicated that there were no significant differences between groups $\left(F_{(1,10)}\right.$ $=2.61 ; p>0.05)$, across time $\left(F_{(9,90)}=1.69 ; p>0.05\right)$, nor was there a significant interaction between treatment and time $\left(F_{(9,90)}\right.$ $=0.71 ; p>0.05)$.

\section{Correlations of behavior and chemistry: Experiments 1 and 2}

When data of all groups tested for spontaneous alternation performance in Experiments 1 and 2 were combined, there was a

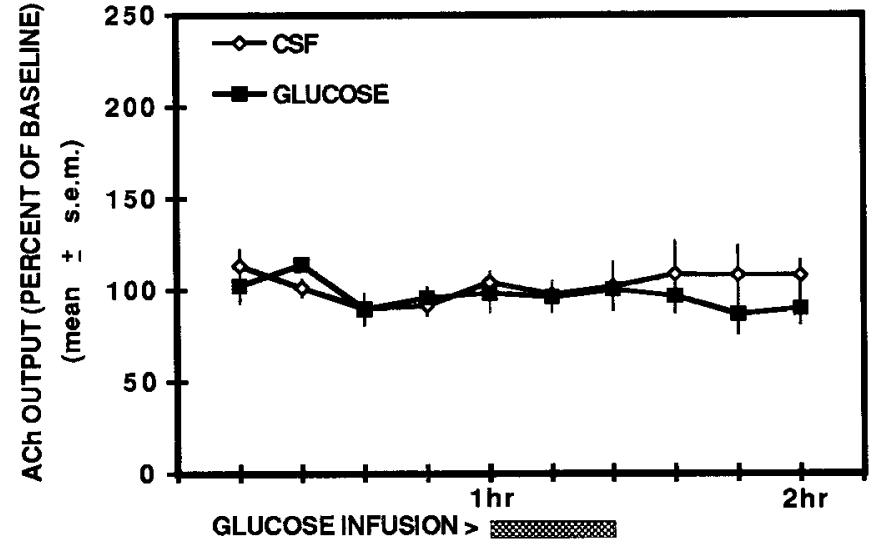

Figure 6. Effects of unilateral hippocampal injections of glucose and artificial cerebrospinal fluid on contralateral hippocampal ACh output in the resting condition. Injections of glucose $(6.6 \mathrm{~mm})$ or CSF did not alter hippocampal ACh output in the resting condition.
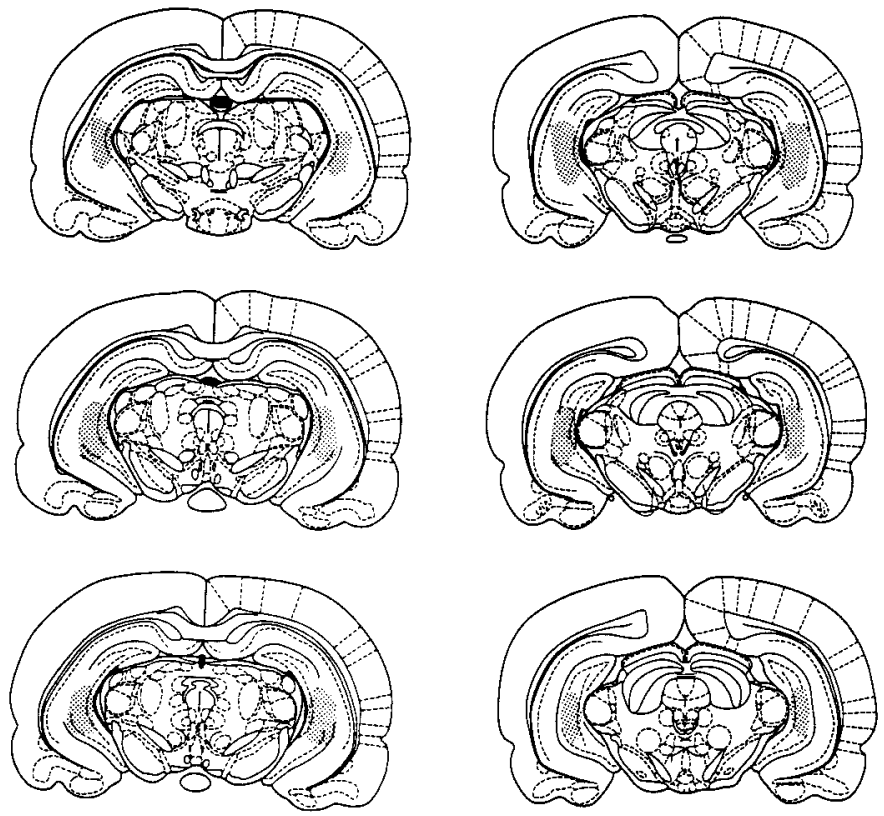

Figure 7. The stippled areas represent the range of probe locations in the hippocampal formation for all rats included in the data analyses for Experiments 1 and 2.

significant correlation between the percent change in ACh output (sample 7) and alternation scores performance $(r=0.62$; df $=22$; $p<0.01)$. However, this correlation reflects the treatment difference between CSF and glucose groups. Correlations within the CSF and glucose groups ( $r=0.37$ and 0.17 , respectively) did not approach statistical significance. Also, for combined groups as well as within the CSF and glucose groups, there were no significant correlations between number of arm entries and either the percent increases in ACh output or alternation scores.

\section{Histology: Experiments 1 and 2}

As illustrated in Figure 7, the dialysis probes were located within the hippocampal formation. There was minor cellular damage that lined the dialysis probe and guide cannula. Probes positions ranged from 4.8 to $6.0 \mathrm{~mm}$ posterior to bregma in the Paxinos and Watson (1986) atlas. The probes were predominantly located in 
the medial portions of the dentate gyrus and CA3 areas and extended ventrally to a level of the rhinal fissure. Differences in probe location within the hippocampal formation did not result in differences in baseline ACh output or glucose-induced increases in ACh output.

\section{DISCUSSION}

The present experiments demonstrated that a unilateral infusion of glucose into the hippocampal formation potentiated the increase in hippocampal ACh output during spontaneous alternation testing. This potentiation of ACh output was observed both ipsilateral and contralateral to the infusion. Finally, glucose infusions into the hippocampal formation augmented spontaneous alternation performance in a four-arm maze.

In CSF controls, hippocampal ACh output remained elevated for at least $12 \mathrm{~min}$ but returned to basal levels by $24 \mathrm{~min}$ after behavioral testing. For the spontaneous alternation condition, both the time course and magnitude of change in ACh output for CSF controls was comparable to previous findings in rats (Ragozzino et al., 1996). The findings from in vivo measurements of ACh output further support results from analyses of highaffinity choline uptake, suggesting that cholinergic neurons projecting to the hippocampal formation are activated during learning and memory (Marighetto et al., 1989, 1994; Wenk et al., 1984).

Previous studies have found that the septohippocampal cholinergic system may be activated in tests that do not explicitly measure learning and memory, i.e., immobilization and locomotor activity (Gilad, 1987; Day et al., 1991). These findings open the possibility that an increase in hippocampal ACh release during spontaneous alternation testing may be the result of stress, novelty, or locomotor activity. However, these explanations seem unlikely. Repeated spontaneous alternation test sessions still produced increases in ACh release comparable to those seen in the first test session (M. Ragozzino, K. Unick, P. Gold, unpublished observations). Furthermore, as also noted previously (Ragozzino et al., 1996), there was no relationship in any of the treatment groups between the number of arm choices and the change in hippocampal ACh output in the present experiments. Moreover, rats that receive multiple training sessions for learning to swim to an escape platform exhibit changes in hippocampal high-affinity choline uptake. In contrast, rats trained in a swimming-only condition do not show changes in hippocampal high-affinity choline uptake (Decker et al., 1988). Taken together, the findings suggest that an activation of the septohippocampal cholinergic system may be important for learning and memory.

A unilateral infusion of glucose into the hippocampal formation during spontaneous alternation testing significantly augmented hippocampal ACh output. The $6.6 \mathrm{~mm}$ concentration of glucose in the treatment group is approximately double that estimated to be in the extracellular fluid of the brain (Silver and Erecinska, 1994). Interestingly, measurements of extracellular glucose levels in particular brain areas indicate that extracellular glucose levels can vary with different behavioral manipulations, i.e., doubling during restraint stress (Fellows and Boutelle, 1993). Thus, the $6.6 \mathrm{~mm}$ concentration inf used through the hippocampal formation is within a physiological range that may occur under certain conditions.

The potentiation of hippocampal ACh output by intrahippocampal glucose infusions during behavioral testing is comparable to findings observed with systemic injections of glucose (Ragozzino et al., 1996). Although it is possible that systemic glucose injections potentiate hippocampal ACh output by acting principally in the hippocampal formation, glucose also affects behavioral performance when injected into other neural regions (Ragozzino et al., 1992; Ragozzino and Gold, 1994a). Therefore, the effects of systemic glucose injections on hippocampal ACh output may be derived at least in part from glucose actions at multiple brain sites.

The second experiment found that intrahippocampal infusions of glucose also potentiated ACh output contralateral to the injection during behavioral testing. On the basis of both anatomical and physiological findings, there is substantial connectivity between the hemispheres of the hippocampal formation (Swanson et al., 1978; Laurberg and Sorsensen, 1981; Finnerty and Jefferys, 1993). However, we believe this is the first demonstration indicating that modulation of neurotransmitter release in one hippocampal hemisphere can alter the release of that neurotransmitter in the other hemisphere during behavioral testing. These neurochemical findings are important not only in understanding the neural mechanisms underlying glucose effects on memory, but also in building a comprehensive view of hippocampal functions and their underlying neural mechanisms. On the basis of histology indicating that the probes were within the hippocampal formation, we believe that the contralateral potentiation of $\mathrm{ACh}$ output is not caused by glucose diffusion into the ventricular system. Possibly, contralateral increases in ACh output reflect glucose actions on hippocampal neurons that project directly to the contralateral hippocampal hemisphere via associational and commissural pathways. Alternatively, unilateral glucose inf usions may have altered neural activity in other brain areas that project to the contralateral hippocampal formation, leading subsequently to the potentiation of $\mathrm{ACh}$ output seen in the contralateral hemisphere. An important example of this latter possibility is that unilateral postsynaptic actions of glucose provide feedback to the cholinergic projection neurons in the medial septum, thereby changing the level of activity in these neurons.

Intrahippocampal glucose injections did not modify hippocampal ACh output under all conditions. When administered during spontaneous alternation testing, unilateral glucose infusions augmented the task-induced increase in ACh output. In marked contrast, when administered to rats at rest, glucose infusions did not modify hippocampal ACh output in the ipsilateral or contralateral side. These findings add to others suggesting that glucose increases ACh output only under conditions in which the activity of cholinergic neurons is "significantly" altered (Stone et al., 1987, 1988b; Ragozzino et al., 1996). For example, systemic glucose injections alone do not induce tremors, but glucose coadministered with physostigmine potentiates the onset and severity of tremors (Stone et al., 1988b). The present results have a further implication, at least for studies of learning and memory. Evaluation of biochemical effects of drug actions should be performed within the context of the behavioral measures. Without behavioral testing at the time that pharmacological measures are obtained, assessments of CNS responses to drugs may potentially produce misleading, or at least limited, results. In the present instance, if glucose had been administered only "off-line" with respect to behavioral testing, we would have concluded erroneously that the treatment had no effect on ACh output.

Intrahippocampal glucose infusions not only augmented hippocampal ACh output, but also produced a concomitant increase in spontaneous alternation performance. Previous findings indicate that inserting delays between arm choices or removing extra maze cues in this task significantly reduces alternation scores (Ragozzino et al., 1996; M.E. Ragozzino, unpublished observa- 
tions), consistent with the idea that this task has a spatial memory component and consistent with a description of the task as a delayed non-matching-to-sample task guided by unknown motivation. These findings suggest that enhancement of memory in the cross maze produced by a unilateral hippocampal infusion of glucose may be at least partially attributable to an increase in $\mathrm{ACh}$ release in this structure. Because the unilateral infusions of glucose produced bilateral augmentation of hippocampal ACh output, the findings do not reveal whether unilateral potentiation of hippocampal ACh output would be sufficient to enhance memory in the cross maze.

One mechanism by which glucose might directly affect the function of cholinergic neurons is by providing a precursor for the synthesis of acetyl-CoA, thereby increasing the availability of acetyl-CoA as a substrate for ACh synthesis. Although highaffinity choline uptake is generally the rate-limiting step for ACh synthesis (Simon et al., 1976), the availability of acetyl-CoA may be rate-limiting in certain conditions (Gibson and Blass, 1976; Bielarczyk and Szutowicz, 1989), i.e., depolarized brain synaptosomes. Thus, glucose administration might modulate ACh synthesis and release by increasing the availability of acetyl-CoA in conditions in which cholinergic neurons are activated. Importantly, however, hyperglycemia or glucose treatment also appears to affect neurochemical systems implicated in learning and memory other than the cholinergic system (Bradford, 1986; Brase et al., 1987; Stone et al., 1991; During et al., 1995). For example, glucose is also critical for the synthesis of glutamate and aspartate and may improve learning and memory by modulating the release of glutamate and aspartate under certain testing conditions (Bradford, 1986). In addition, intrahippocampal infusions of glucose may enhance spontaneous performance through direct actions on several neurotransmitter systems, perhaps by regulating neurotransmitter release via modulation of $\mathrm{K}^{+}$-ATP channels (Amoroso et al., 1990; During et al., 1995; Stefani et al., 1996). Although the mechanisms underlying glucose effects on memory are still unknown, these findings add to accumulating evidence suggesting that the effect of glucose on brain functioning is not limited to its use as an energy source but that it may also play an important role in synaptic transmission.

In conclusion, the present findings indicate that unilateral infusions of glucose into the hippocampal formation enhance spontaneous alternation performance in a cross maze. Behavioral testing produces an increase in hippocampal ACh output, which is potentiated by unilateral glucose infusions into the hippocampal formation. The test-related potentiation of hippocampal ACh output by glucose treatment occurs in both the ipsilateral and contralateral hippocampal formation. In contrast, unilateral glucose infusions do not modify hippocampal ACh output during the resting condition. The results suggest that an increase in hippocampal ACh output contributes to the memory improvement in the cross maze. Furthermore, because glucose potentiated ACh output in the behavioral but not the resting condition, glucose may modify ACh output only in conditions in which there is an increase in cholinergic activity.

\section{REFERENCES}

Amoroso S, Schmid-Antomarchi H, Fosset M, Lazdunski M (1990) Glucose, sulfonylureas, and neurotransmitter release: role of ATP-sensitive $\mathrm{K}^{+}$channels. Science 247:852-854.

Bielarczyk H, Szutowicz A (1989) Evidence for the regulatory function of synaptoplasmic acetyl-CoA in acetylcholine synthesis in nerve endings. Biochem J 262:377-380.

Bradford HF (1986) Chemical neurobiology. New York: Freeman.
Brase DA, Han YH, Dewey WL (1987) Effects of glucose and diabetes on binding of naloxone and dihydromorphine to opiate receptors in mouse brain. Diabetes 36:1173-1177.

Day J, Damsma G, Fibiger HC (1991) Cholinergic activity in the rat hippocampus, cortex and striatum correlates with locomotor activity: an in vivo microdialysis study. Pharmacol Biochem Behav 38:723-729.

Decker MW, Pelleymounter MA, Gallagher M (1988) Effects of training on a spatial memory task on high affinity choline uptake in hippocampus and cortex in young adult and aged rats. J Neurosci 8:90-99.

During MJ, Leone P, Davis KE, Kerr D, Sherwin RS (1995) Glucose modulates rat substantia nigra GABA release in vivo via ATP-sensitive potassium channels. J Clin Invest 95:2403-2408.

Durkin TP, Messier C, DeBoer P, Westerwink BHC (1992) Raised glucose levels enhance scopolamine-induced acetylcholine overflow from the hippocampus: an in vivo microdialysis study in the rat. Behav Brain Res 49:181-188.

Fellows LK, Boutelle MG (1993) Rapid changes in extracellular glucose levels and blood flow in the striatum of the freely moving rat. Brain Res 604:225-231.

Finnerty GT, Jefferys JGR (1993) Functional connectivity from CA3 to the ipsilateral and contralateral CA1 in the rat dorsal hippocampus. Neuroscience 56:101-108.

Gibbs EL, Lennox WG, Nims LF, Gibbs FA (1942) Arterial and cerebral venous blood: arterial-venous differences in man. J Biol Chem 144:325-332.

Gibson GE, Blass JP (1976) Impaired synthesis of acetylcholine in brain accompanying mild hypoxia and hypoglycemia. J Neurochem 27:37-42.

Gilad GM (1987) The stress-induced response of the septo-hippocampal cholinergic system. A vectorial outcome of psychoneuroendocrinological interactions. Psychoneuroendocrinology 12:167-184.

Gold PE (1986) Glucose modulation of memory storage processing. Behav Neural Biol 45:342-349.

Hall JL, Gonder-Frederick LA, Chewning WW, Silveira J, Gold PE (1989) Glucose enhancement of performance on memory tests in young and aged humans. Neuropsychologia 27:1129-1138.

Laurberg S, Sorensen KE (1981) Associational and commissural collaterals of neurons in the hippocampal formation (hilus fasciae dentatae and subfield CA3). Brain Res 212:287-300.

Lee MK, Graham SN, Gold PE (1988) Memory enhancement with posttraining intraventricular glucose injections in rats. Behav Neurosci 102:591-595.

Manning CA, Hall JL, Gold PE (1990) Glucose effects on memory and other neuropsychological tests in elderly humans. Psychol Sci 1:307-311.

Manning CA, Ragozzino ME, Gold PE (1993) Glucose enhancement of memory in patients with Alzheimer's disease. Neurobiol Aging 14:523-528.

Marighetto A, Durkin T, Toumane A, Lebrun C, Jaffard R (1989) Septal-noradrenergic antagonism in vivo blocks the testing-induced activation of septohippocampal cholinergic neurones and produces a concomitant deficit in working memory performance. Pharmacol Biochem Behav 34:553-558.

Marighetto A, Micheau J, Jaffard R (1994) Effects of intraseptally injected glutamatergic drugs on hippocampal sodium-dependent highaffinity choline uptake in "naive" and "trained" mice. Pharmacol Biochem Behav 49:689-699.

Messier C, White NM (1987) Memory improvement by glucose, fructose, and two glucose analogs: a possible effect on peripheral glucose transport. Behav Neural Biol 48:104-127.

Packard MG, White NM (1990) Effect of posttraining injections of glucose on acquisition of two appetitive learning tasks. Psychobiology 18:282-286.

Pardridge WM (1983) A perspective from the blood-brain barrier. Physiol Rev 63:1481-1535.

Paxinos G, Watson C (1986) The rat brain in stereotaxic coordinates. Orlando, FL: Academic.

Pellegrino LJ, Pellegrino AS, Cushman AJ (1979) A stereotaxic atlas of the rat brain. New York: Plenum.

Ragozzino ME, Parker ME, Gold PE (1992) Spontaneous alternation and inhibitory avoidance impairments with morphine injections into the medial septum: attenuation by glucose administration. Brain Res 597:241-249.

Ragozzino ME, Gold PE (1994a) Task-dependent effect of intraamygdala morphine injections: attenuation by intra-amygdala glucose injections. J Neurosci 14:7478-7485. 
Ragozzino ME, Wenk GL, Gold PE (1994b) Glucose attenuates morphine-induced decrease in hippocampal acetylcholine output: an in vivo microdialysis study in rats. Brain Res 655:77-82.

Ragozzino ME, Gold PE (1995a) Glucose injections into the medial septum reverse the effects of intraseptal morphine infusions on hippocampal acetylcholine output and memory. Neuroscience 68:981-988.

Ragozzino ME, Hellems K, Lennartz RC, Gold PE (1995b) Pyruvate infusions into the septal area attenuate spontaneous alternation impairments induced by intraseptal morphine injections. Behav Neurosci 109:1074-1080.

Ragozzino ME, Unick KE, Gold PE (1996) Hippocampal acetylcholine release during memory testing in rats: augmentation by glucose. Proc Natl Acad Sci USA 93:4693-4698.

Silver IA, Erecinska M (1994) Extracellular glucose concentration in mammalian brain: continuous monitoring of changes during increased neuronal activity and upon limitation in oxygen supply in normo-, hypo-, and hyperglycemic animals. J Neurosci 14:5068-5076.

Simon JR, Atweh S, Kuhar MJ (1976) Sodium-dependent high affinity choline uptake: a regulatory step in the synthesis of acetylcholine. J Neurochem 26:909-922.

Stefani MR, Nicholson GM, Gold PE (1996) Enhancement of spontane- ous alternation scores in the rat by intra-septal injection of the K-ATP channel blocker glibenclamide. Soc Neurosci Abstr 22:141.

Stone WS, Cottrill KL, Gold PE (1987) Glucose and epinephrine attenuation of scopolamine-induced increases in locomotor activity in mice. Neurosci Res Commun 1:105-111.

Stone WS, Croul CE, Gold PE (1988a) Attenuation of scopolamineinduced amnesia in mice. Psychopharmacology 96:417-420.

Stone WS, Cottrill KL, Walker DL, Gold PE (1988b) Blood glucose and brain function: interactions with CNS cholinergic systems. Behav Neural Biol 50:325-334.

Stone WS, Walser B, Gold SD, Gold PE (1991) Scopolamine- and morphine-induced impairments of spontaneous alternation performance in mice: reversal with glucose and with cholinergic and adrenergic agonists. Behav Neurosci 105:264-271.

Stone WS, Rudd RJ, Gold PE (1995) Glucose attenuation of atropineinduced deficits in paradoxical sleep and memory in rats. Brain Res 694:133-138.

Swanson LW, Wyss JM, Cowan WM (1978) An autoradiographic study of the organization of intrahippocampal associational pathways in the rat. J Comp Neurol 181:681-716.

Wenk G, Hepler D, Olton D (1984) Behavior alters the uptake of $\left[{ }^{3} \mathrm{H}\right]$ choline into acetylcholinergic neurons of the nucleus basalis magnocellularis and medial septal area. Behav Brain Res 13:129-138. 